\title{
WAVE-INDUCED LOADS ON CROSS-DECK OF A WAVE-PIERCING TRIMARAN WITH DIFFERENT HULL FORMS OF OUTRIGGERS
}

\author{
Abolfath ASKARIAN KHOOB ${ }^{1,2}$, Mohammad Javad KETABDARI ${ }^{3 *}$ \\ ${ }^{1,3}$ Dept of Marine Technology, Amirkabir University of Technology, Tehran, Iran \\ ${ }^{2}$ Marine Faculty of Imam Khomeini Maritime University, Nowshahr, Iran
}

Received 6 July 2016; revised 16 October 2016; accepted 4 February 2017

\begin{abstract}
Trimaran has unique hull form with a rapidly growth in recent years due to its application as a mode of transports and naval vessels. Designing trimaran faces many technical challenges because of its complex structural outlines and high-speeds operation. This article investigates the influence of side hulls configuration (symmetric, inboard and outboard types) for wave loads on cross-deck of a trimaran ship when advancing at sea in regular waves. The computation of these hydrodynamic forces is carried out using MAESTRO-Wave 3D panel method code. This code is based on potential flow theory that uses Green's function with the forward speed correction in the frequency domain. The results demonstrate that the outboard side hull form has the best performance on wave-induced load among three kinds of side hull forms. Furthermore, the results of this study offer more information for selecting the side hull form of the trimaran.
\end{abstract}

Keywords: trimaran ship, cross-deck, frequency domain computation, wave-induced loads, side hull, high-speed.

\section{Introduction}

High-speed on the sea with minimum power requirement has been a major design objective for a long time by marine engineers. In the last years, a rapid growth of interest in the development of high-speed multi-hull vessels for fast sea transportation has shown for both commercial and military purposes. The multi-hull ship term refers to a group of vessels consist of various numbers of hulls with common or uncommon shapes such as the catamaran (two demi-hulls), the trimaran (three sub-hulls) and the pentamaran (five sub-hulls). Multi-hull ships due to its inherent advantages such as better seaworthiness, higher initial stability, broad open decks, better speed-power performance and safety are currently used as fast passenger transport and cargo ships, as naval operational vessels, and as leisure craft in austere harbours and regions characterized by harsh sea states. Trimaran is a multi-slenderhulled vehicle, which consists of a long slender main hull and two smaller symmetric or asymmetric outer hulls attached to the main hull by lateral strut that is usually referred to as a cross-structure or simply as a cross-deck.

Trimaran is a novel hull form intermediate design solution between the monohull and the catamaran displacement ship, which combines the best of both worlds between monohulls and catamarans to reduce the problem with the high fuel consumption, large cargo capacity and high-speed operation. Because of its unique structure the trimaran configuration possesses several advantages over contemporary conventional monohull and other highspeed crafts:

- excellent fuel consumption efficiency because of low resistance at high-speed;

- quick accelerating performance because of slender main and side hulls;

- high stability due to the suitable alignment of lateral hulls;

- larger deck area for equipment, transport capacity, and arrangement convenience;

- strong survivability, added collision protection and damaged stability inherent;

- superior seakeeping quality due to longer waterline length, particularly in head and bow quartering seas;

- low building costs as a result of the possibility of using steel material and the reduction in the propulsion machinery system.

Configuration, size, longitudinal positions (staggers) and lateral positions (clearances) of side hulls has a significant effect on the stability, dynamic behaviour, seakeeping performance and wave-induced structural loads. In con-

*Corresponding author. E-mail: ketabdar@aut.ac.ir 
trast to traditional monohull ships, which are exposed to longitudinal wave loads, trimaran is also exposed to transverse wave loads because of its cross structure.

Some researchers studied on the advancement of trimaran in sea waves. Ackers et al. (1997) carried out the investigation of the interference effect between the main hull and the side hull of trimaran with three kinds of side hull configuration (symmetric, inboard and outboard types). The results reported that side hull symmetry has a significant effect on interference drag. The asymmetric inboard configuration experiences exaggerated interference effect and the asymmetric outboard configuration produces a narrower range of interference drag. The symmetric hulls produce a moderate range of interference drag, closer to the asymmetric inboard configuration. Therefore, optimum side hulls for a trimaran might be selected based on a tradeoff between symmetry, to minimize baseline resistance, and asymmetry outboard to minimize interference drag.

Brizzolara (2003) conducted systematic model tests and theoretical analysis aimed to the assessment of the seaworthiness of the two different trimaran designs. The first having a rounded main hull and hard chine asymmetric wing hulls. The second having hard chine main hull and symmetric round bilge wing hulls. They showed that the second design, featuring the deep- $\mathrm{V}$ main hull result in clearly better vertical motion performance at highspeed, especially for heave motion.

The first studies on wave loading of the trimaran crossdeck was performed by Rhoads (2004). He used simple and symmetric box-type hull shapes for each of the three hulls. This study used analytical approximations and its results were compared with those of 3D Finite Element Method (FEM) analysis of the ship using MAESTRO (Maestromarine 2016). Results show that analytical and numerical data are in a good agreement. Ungaro et al. (2004) evaluated the global strength of a trimaran in head seas with three configurations of side hull. They calculated the long term loads in several sea zones based on the results of a 3D seakeeping panel method. Then a 3D FEM simulation of the ship was carried out using MAESTRO to study the hull structure response. Dyachkov and Makov (2005) presented a complex method for calculation of wave-induced motion of a fast displacement catamaran.

Fang and Too (2006) predicted the effect of side hull location on the motions of a trimaran using the $3 \mathrm{D}$ source distribution method. They showed that predicted results are in accordance with experimental data. Ogawa (2008) predicted the effect of the side hulls arrangement on the wave loads of the multi-hull ship using Newman's unified theory. He showed that present method is in a good agreement with experimental data and numerical solution by 3D panel method at zero speed. Dabssi et al. (2008) developed numerical and hydrodynamical procedures to compute hydrodynamic coefficients and forces on multihulls in shallow water. Fang and Chen (2008) conducted a spectral analysis based on the wave-induced loads to select suitable side hull location for a trimaran ship advancing in waves. They applied the 3D source distribution method, using a combination of pulsating source potential and the panel method, to drive wave load with respect to different staggers and clearances.

Xu and Zhang (2011) calculated significant values for wave loads of a trimaran with different layouts and lengths of side hulls based on 3D potential theory and Green's function. Liu et al. (2011) estimated longitudinal ultimate strength of a trimaran by testing and numerical simulation with nonlinear FEM. Ren et al. (2012) built the global FEM of a trimaran in accordance with the trimaran rules. They used some modifications such as increasing the size of the connection of the main hull and cross-deck. They also increased the thickness of bulkhead and wet deck and improved the structure size. These led to reduction of the stress concentration. Bashir et al. (2013) predicted the wave-induced loads on a deep- $\mathrm{V}$ catamaran using model tests. The obtained results were compared with the numerical predictions carried out using a 3D panel method code MAESTRO-Wave (Maestromarine 2016) based on potential flow theory. Based on their work the predicted and measured results were in a good agreement. Zhao et al. (2013) presented a method to apply strip theory based linear seakeeping pressure loads to 3D Finite Element (FE) models. Analysis was performed using MAESTRO-Wave. The results showed that the proposed method is in excellent agreement with the ordinary strip theory method applied in ShipX (VERES) (https://www.sintef.no/en/software/shipx). Senan and Krishnankutty (2012) estimated the non-linear wave-induced load and motion response of a three hulls carrier vessel. Panel method and FEM were used for numerical estimation of the forces and motions of the vessel.

Mohammadi et al. (2015) calculated the global loads acting on a trimaran in intact and damage conditions. They used strip theory and panel method to predict still water static and wave-induced dynamic loads in the frequency domain. The analysis carried out using ShipX (VERES) and MAESTRO-Wave codes. Comparison of the results shows a good agreement between results of the two numerical solutions. Dobashi (2014) developed a method based on strip theory (STF method) to predict effect of side hulls location on wave loads of cross-deck of trimaran. They validated their method with experimental data and confirmed that it can evaluate qualitatively effect of the side hull position for wave loads in head seas. Fuentes et al. (2015) employed FEM to study an aluminium trimaran for identification locations with high stress. They developed a structural optimisation by using a discreet approach to geometrical modification of the structure in highly stress regions. This procedure reduced the material from 17 to $25 \%$ without exceeding allowable stresses prescribed by classification rules.

Configuration of side-hulls plays an important role in the wave-induced motions and loads of the trimaran. From the broad literature review as above it is evident, that majority of studies in this field focused on the symmetric form of side hulls. While the effect of side hull configuration on wave-induced loads of trimaran especially crossdeck structure has been rarely investigated. Therefor in this research, the 3D panel method code of MAESTRO-Wave 
was used to calculate the significant values for wave loads of trimaran with three kinds of side hull configuration (symmetric, inboard and outboard types). The aim of this study is to determine suitable configuration for side hulls in structural points of view.

\section{Principal dimensions and structural design}

In this work, a design model for the trimaran was developed based on requirements and constraints of American Bureau of Shipping (ABS) rules for high-speed naval crafts (ABS 2014). Moreover, the reports on designing models of trimaran ship, including $R V$ Triton, Independence (LCS-2), Bechijiqua Express and Austal 102 were employed in the present study. Form of the centre hull is quite slender while in outriggers they are in Wigley hull forms. Bow profile of main hull is wave piercing to improve hydrodynamic performance of the ship.

A global FEM of trimaran was simulated in the full load condition based on the ABS rules. The marine steel grade of AH36 was used as the structural material for the model to achieve lower building cost and fatigue. Main tanks and compartments were located in both central and side hulls of the model. Main ship components and payloads (deckhouse, basic machinery and generators) were modelled as weights, which are distributed on a certain number of nodes. The structural configuration of the model for the main hull, outriggers and cross-decks is a longitudinal framing system with frame spaces of $1000 \mathrm{~mm}$. Special considerations were taken into account at the junctions of cross-decks and the main hull to avoid stress concentration on the main hull. According to the ABS rules, minimum scantlings were defined for each member and strength of the midship section was controlled with respect to the global and local design loads (ABS 2014).

Trimaran principle dimensions shown in Figure 1 are reported in Table 1. Figure 1, shows the main hull and three kinds of side-hulls (symmetric, inboard and outboard types).

Table 1. Main particulars of the trimaran

\begin{tabular}{|l|c|}
\hline \multicolumn{1}{|c|}{ Item } & Value \\
\hline Length overall [m] & 121 \\
\hline Length on waterline [m] & 120.2 \\
\hline Length between perpendiculars [m] & 117.31 \\
\hline Beam overall [m] & 24.17 \\
\hline Beam on waterline [m] & 10.66 \\
\hline Depth [m] & 13.03 \\
\hline Draft [m] & 4.86 \\
\hline Length of side hull [m] & 40 \\
\hline Beam of side hull [m] & 2.62 \\
\hline Depth of side hull [m] & 9.04 \\
\hline Draft of side hull [m] & 3.20 \\
\hline $\begin{array}{l}\text { Clearance between the centreline of the main hull } \\
\text { and the centreline of the side hull [m] }\end{array}$ & 10.77 \\
\hline $\begin{array}{l}\text { Stagger between the mid-ship of side hull and the } \\
\text { mid-ship of main hull [m] }\end{array}$ & 25.41 \\
\hline Displacement (tonnage) [ton] & 2435.93 \\
\hline Design speed [knot] & 30 \\
\hline
\end{tabular}

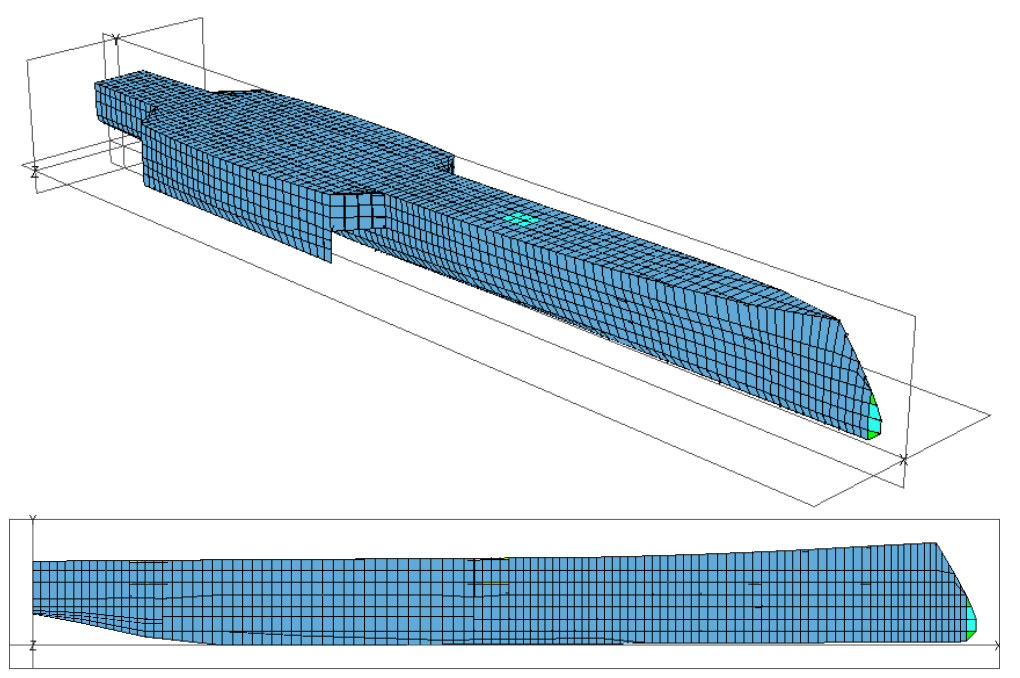

a)

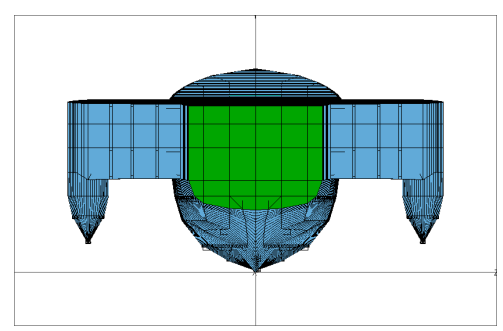

b)

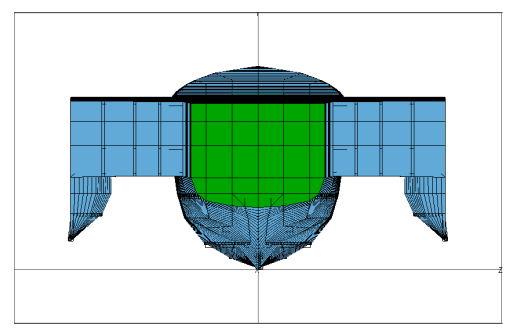

c)

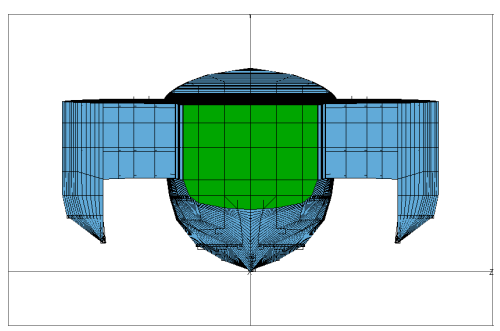

Figure 1. FE model of trimaran and three kinds of side-hull forms: $a$ - symmetric; b - inboard; c - outboard 


\section{Theoretical background}

A 3D panel linear code called MAESTRO-Wave was used to predict the wave loads of this vessel (Maestromarine 2016). This program uses the Green's function integral equation's technique to determine the unsteady potentials in order to solve the Boundary Value Problem (BVP) of interaction between water waves and bodies in the frequency domain.

Consider a trimaran ship advancing at constant speed $U$. The amplitude of ship motions as well as of the incident waves are supposed to be small, while The fluid is assumed to be ideal, (inviscid, incompressible and irrotational). The total velocity potential in the fluid domain can be expressed as:

$$
\Psi(x, y, z ; t)=-U \cdot x+\varphi(x, y, z)+\phi(x, y, z ; t),
$$

where: $U$ introduces a steady basis flow; $\varphi(x, y, z)$ is the disturbance potential due to body in the steady flow; the total unsteady wave potential $\phi(x, y, z ; t)$ due to the incident wave and vessel's response is a superposition of the series of independent velocity potentials: potentials due to an incident wave $\phi_{0}$, diffracted wave on the fixed body $\phi_{7}$ and the six radiation wave components due to the six body motions $\phi_{i}(i=1,2,3,4,5,6)$.

The unsteady potential can be written as follows:

$$
\begin{aligned}
& \phi=\left(A \cdot\left(\varphi_{0}+\varphi_{7}\right)+\sum_{i=1}^{6} \xi_{i} \cdot \varphi_{i}\right) \cdot e^{i \cdot \omega \cdot t}, \\
& i=1,2,3,4,5,6 .
\end{aligned}
$$

where: $\varphi_{0}, \varphi_{7}, \varphi_{i}$ are the unit potentials; $A$ is the amplitude of the incident wave; $\xi_{i}$ is the motion displacement $(i=1$, $2,3,4,5,6$ - represents surge, sway, heave, roll, pitch and yaw, respectively); $\omega$ is the frequency of encounter, which is related to the ship's speed $U$, the incident wave frequency $\omega_{0}$, the wave number $k=\frac{\omega_{0}^{2}}{g}$ and relative heading to the incident wave direction $\beta .^{g}$

Frequency of encounter $\omega$ is defined as follows:

$$
\omega=\left|\omega_{0}-U \cdot \cos \beta\right| \text {. }
$$

The incident wave potential for infinite deep water is expressed as:

$$
\varphi_{0}=i \cdot \frac{g}{\omega_{0}} \cdot e^{k \cdot(z-i \cdot x \cdot \cos \beta-i \cdot \cdot \cdot \sin \beta)} .
$$

The disturbance, radiation and diffraction potentials must satisfy Laplace equation and following linear boundary conditions are given in Table 2.

The disturbance and the velocity potentials are obtained to solving this BVPs using the Boundary Integral Equation (BIE) technique by means of the Kelvin type of Green's function. The source formulation is used, so that the velocity potentials are represented by the source distribution over the wet part of the body. The double body

\begin{tabular}{|c|c|c|c|}
\hline Location & Steady & Radiation & Diffraction \\
\hline $\begin{array}{l}\text { In the } \\
\text { fluid }\end{array}$ & $\nabla^{2} \phi=0$ & $\nabla^{2} \varphi_{i}=0$ & $\nabla^{2} \varphi_{7}=0$ \\
\hline $\begin{array}{l}\text { Free } \\
\text { surface }\end{array}$ & $\frac{\partial \phi}{\partial z}=0$ & $\frac{\partial \varphi_{i}}{\partial z}-k \cdot \varphi_{i}=0$ & $\frac{\partial \varphi_{7}}{\partial z}-k \cdot \varphi_{7}=0$ \\
\hline Body & $\frac{\partial \phi}{\partial n}=0$ & $\frac{\partial \varphi_{i}}{\partial n}=i \cdot \omega \cdot n_{i}+m_{i}$ & $\frac{\partial\left(\varphi_{7}+\varphi_{0}\right)}{\partial n}=0$ \\
\hline Bottom & $\frac{\partial \phi}{\partial n}=0$ & $\frac{\partial \varphi_{i}}{\partial n}=0$ & $\frac{\partial \varphi_{7}}{\partial n}=0$ \\
\hline \multicolumn{4}{|c|}{$\begin{array}{l}\text { Notes: } \\
\vec{r}=(x, y, z) ; \\
\vec{n}=\left(n_{1}, n_{2}, n_{3}\right) ; \\
\left(n_{4}, n_{5}, n_{6}\right)=\vec{r} \times \vec{n} ; \\
\left(m_{1}, m_{2}, m_{3}\right)=-(\vec{n} \cdot \nabla) \cdot \nabla \Phi ; \\
\left(m_{4}, m_{5}, m_{6}\right)=-(\vec{n} \cdot \nabla) \cdot(\vec{r} \times \nabla \Phi) .\end{array}$} \\
\hline
\end{tabular}
potential is:

$$
\varphi(p)=\oiint_{s} G_{0}(p, q) \cdot \sigma(q) d s
$$

Table 2. BVPs of the potential flows

and the radiation and diffraction potential is:

$$
\begin{aligned}
& \varphi_{i}(p)=\oiint_{s} G(p, q) \cdot \sigma_{i}(q) d s+ \\
& \frac{U^{2}}{g} \cdot \oint_{W L} G(p, q) \cdot \sigma_{i}(q) \cdot n_{1} d l,
\end{aligned}
$$

where: $G(p, q)$ is the Kelvin type of Green's function at a field point $p$ due to an unknown source density of a source point $q ; G_{0}$ is the simple Green's function; $\sigma$ is the panel source strength; $S$ represents the outer wet part of the ship. The source strength $\sigma$ of each potential can be determined by the following BIE:

Double body potential:

$$
2 \cdot \pi \cdot \sigma(p)+\oiint_{s} \frac{\partial G_{0}(p, q)}{\partial n} \cdot \sigma(q) d s=n_{1} \cdot U
$$

Radiation potential $(i=1,2,3,4,5,6)$ :

$$
\begin{aligned}
& 2 \cdot \pi \cdot \sigma_{i}(p)+\oiint_{s} \frac{\partial G(p, q)}{\partial n} \cdot \sigma_{i}(q) d s+ \\
& \frac{U^{2}}{g} \oiint_{W L} G(p, q) \cdot \sigma_{i}(q) \cdot n_{1} d l=i \cdot \omega \cdot n_{i}+m_{i} .
\end{aligned}
$$

\section{Diffraction potential:}

$$
\begin{aligned}
& 2 \cdot \pi \cdot \sigma_{7}(p)+\oiint_{s} \frac{\partial G(p, q)}{\partial n} \cdot \sigma_{7}(q) d s+ \\
& \frac{U^{2}}{g} \oiint_{W L} G(p, q) \cdot \sigma_{7}(q) \cdot n_{1} d l=-\frac{\partial \varphi_{0}}{\partial n} .
\end{aligned}
$$

From the solutions of the integral Equations (7) and (8) by usual numerical routines after discretizing the body surface in a finite number of flat panels, source densities can be calculated. Once the potentials are obtained, the pressure of the body surface on wave can be calculated by the Bernoulli's equation:

$$
p=-\rho \cdot\left(\psi_{t}+\frac{1}{2} \cdot \nabla \psi+\nabla \psi-\frac{1}{2} \cdot U^{2}+g \cdot z\right) .
$$


A first order Taylor expansion of $p$ about the mean position of the body gives:

$$
\begin{aligned}
& p=-\rho \cdot\left(\frac{1}{2} \cdot \nabla \Phi+\nabla \Phi-\frac{1}{2} \cdot U^{2}+g \cdot z\right)- \\
& \rho \cdot\left(\phi_{t}+\nabla \Phi \cdot \nabla \phi\right)-\rho \cdot\left((\vec{a} \cdot \nabla) \cdot\left(\frac{\nabla \Phi \cdot \nabla \phi}{2}+g \cdot z\right)\right) .
\end{aligned}
$$

Then the exciting force $X_{i}$, added mass $a_{i j}$, damping coefficient $b_{i j}$ and restoring coefficient $c_{i j}$ can be obtained and equations of motions can be written as below:

$$
\sum_{j=1}^{6}\left(-\omega^{2} \cdot\left(M_{i j}+a_{i j}\right)+i \cdot \omega \cdot b_{i j}+c_{i j}\right) \cdot \xi_{j}=X_{i},
$$

where: $M_{i j}$ is the mass matrix.

The Response Amplitude Operator (RAO) $\xi_{j},(j=1$, $2,3,4,5,6)$ can be obtained by solving the complex coefficient linear equation group (Equation (11)). The waveinduced bending moment $B M$ and shear force $S F$ in wave are defined as:

$$
\left[\begin{array}{l}
Q_{x} \\
Q_{y} \\
Q_{z} \\
M_{x} \\
M_{y} \\
M_{z}
\end{array}\right]=\iint_{B} P \cdot\left[\begin{array}{l}
n_{1} \\
n_{2} \\
n_{3} \\
n_{4} \\
n_{5} \\
n_{6}
\end{array}\right] d s-\omega^{2} \cdot[M] \cdot\left[\begin{array}{l}
\xi_{1} \\
\xi_{2} \\
\xi_{3} \\
\xi_{4} \\
\xi_{5} \\
\xi_{6}
\end{array}\right] .
$$

The definition of the wave-induced forces and moments acting on cross-deck are shown in Figure 2.

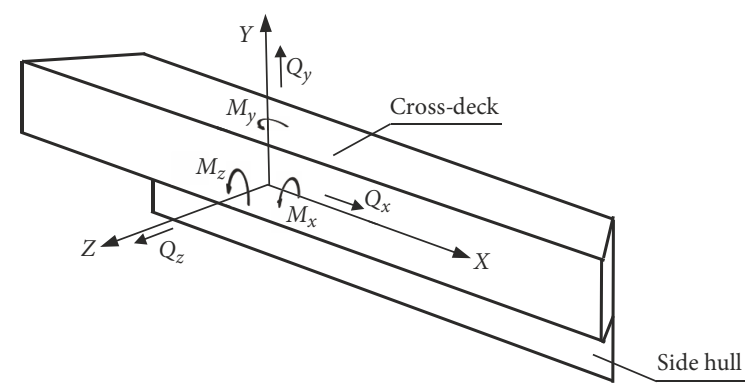

Figure 2. Representation of the wave-induced forces and moments acting on cross-deck

These forces and moments include: longitudinal inplane force $Q_{x}$, transverse vertical shear forces $Q_{y}$, transverse in-plane horizontal force or side force $Q_{z}$, transverse vertical bending moments or roll moment $M_{x}$, horizontal in-plane moments or yaw moment $M_{y}$ and transverse torsional moment or pitch moment $M_{z} \cdot M_{x}, M_{y}$ and $Q_{y}$ are very important for cross structure analysis.

\section{MAESTRO-Wave computational verification}

MAESTRO software is a naval architecture based design tool, which seamlessly integrates hydrodynamics, FE analysis, limit state failure mode evaluation, ultimate hull girder analysis, structural optimization, extreme load analysis and spectral fatigue analysis under a single user interface (Maestromarine 2016). This is a commercial powerful ship design, analysis and evaluation program that is currently used by the navies, classification societies, design offices and universities.

The MAESTRO-Wave is a frequency domain 3D-panel potential flow seakeeping module that is seamlessly has been integrated into the MAESTRO global structural analysis software. The code has been developed based on the potential flow theory using the 3D panel method that makes use of the zero speed Green's function with a forward speed correction in the frequency domain as used in this investigation, (Maestromarine 2016). The code is used for the predictions of motions and wave-induced load response characteristics of marine vehicles and installations in deep water and shallow water conditions including catamarans and trimaran. The main attraction for using this software is that it does not require the use of FE mesh separate from the hydrodynamic mesh when performing the structural analysis of the same hull geometry. This process therefore ensures that there is equilibrium between the hydrodynamic and the FE mesh; hence, it reduces the difficulty of convergence between the two different meshes, which is commonly experienced when importing hydrodynamic mesh into an FE program.

The S-175 container ship is well known standard test case because it was used by the Kim (2010) to carry out a comparative numerical study of linear wave-induced motions and structural loads. The database that resulted from that study includes numerical results from many institutions, and also some experimental data. In order to validate the theoretical capacity of MAESTRO-Wave to predict the motion characteristics of ship hull forms over a range of wave frequencies and Froude numbers comparison was conducted with the available experimental data of S-175. Main particulars of the S-175 container ship shown in Figure 3 are reported in Table 3.

The motion RAO results and wave-induced loads, along with the available experimental data from research by Kim (2010), are shown in Figures 4 and 5. All results are presented in a non-dimensional way using wave amplitude $A$, wave number $k$, encounter frequency $\omega$, water density $\rho$, gravitational acceleration $g$, ship beam $B$ and ship length between perpendiculars $L P P$ as given in Table 3 . Comparison showed that this method has an acceptable accuracy for predicting wave-induced loads and motion of ship.

\section{Results and discussions}

In this article, three kinds of side hull form (symmetric, inboard and outboard types) were utilized to find out the influence of side hull configuration on wave-induced loads acting on cross-deck. All three forms had the same hydrostatic properties and wetted surface area, despite their different cross sections. The speed of vessel was 30 knots (corresponding to Froude number of 0.45 ). The wave headings were beam seas $\left(90^{\circ}\right)$, bow quartering seas $\left(135^{\circ}\right)$ and head seas $\left(180^{\circ}\right)$. The angular frequencies of waves were from 0.21 to $2.1 \mathrm{rad} / \mathrm{s}$. Bretschneider spectrum was taken as the importing spectrum to get the wave response spectrum. In order to study the wave loads on 
a)

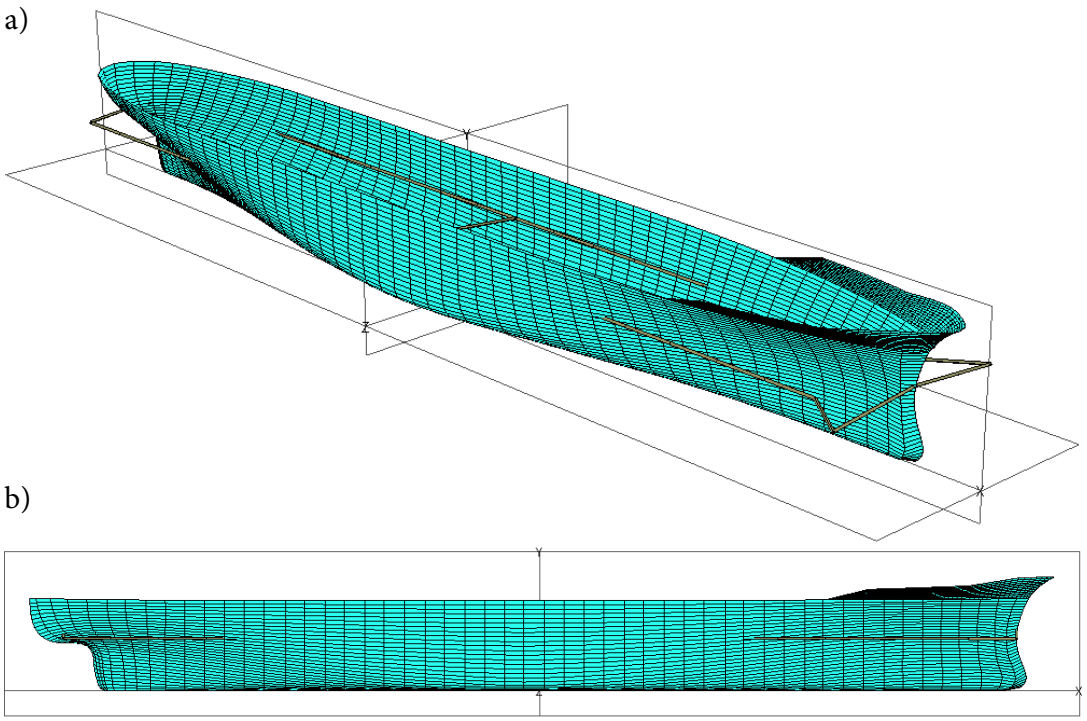

Figure 3. FE model of S-175 container ship: a - 3D model; b - profile view
Table 3. Main particulars of the S-175 container ship

\begin{tabular}{|l|c|}
\hline \multicolumn{1}{|c|}{ Item } & Value \\
\hline $\begin{array}{l}\text { Length between } \\
\text { perpendiculars [m] }\end{array}$ & 175 \\
\hline Beam [m] & 25.4 \\
\hline Depth [m] & 15.4 \\
\hline Draft [m] & 9.5 \\
\hline $\begin{array}{l}\text { Longitudinal center of gravity } \\
\text { aft of midship [m] }\end{array}$ & 2.5 \\
\hline XG (from AP) [m] & 84.97 \\
\hline Vertical center of gravity [m] & 9.55 \\
\hline YG (from centerline) [m] & 0 \\
\hline Block coefficient & 0.572 \\
\hline Midship section coefficient & 0.98 \\
\hline Displacement [t] & 24742 \\
\hline Design speed [knot] & 22.145 \\
\hline
\end{tabular}
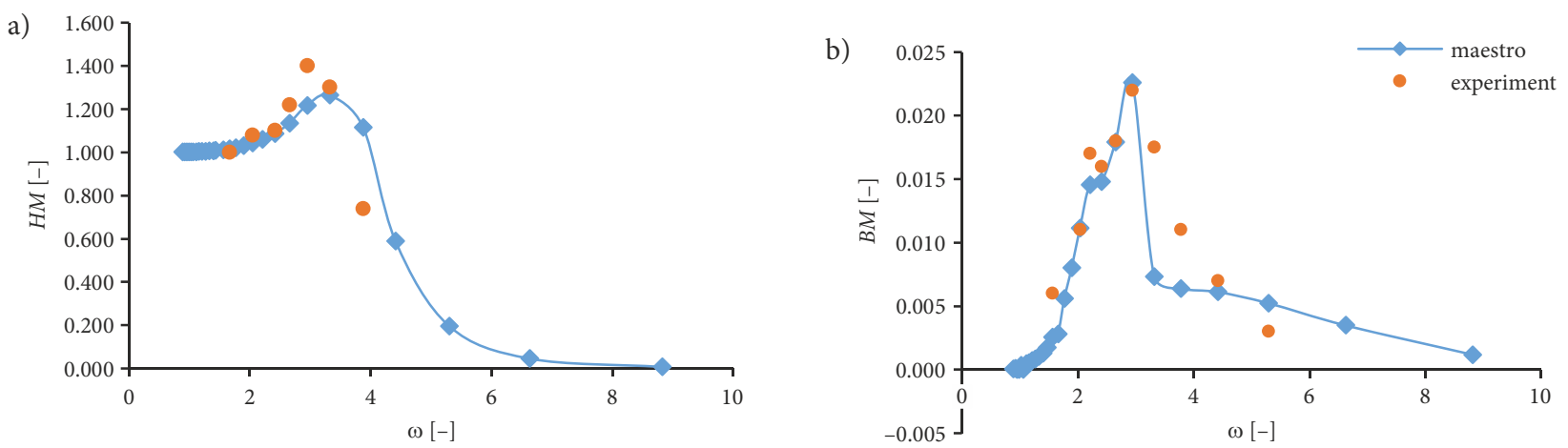

Figure 4. Heave motion $H M$ in beam seas (a) and vertical bending moments $B M(\mathrm{~b})$ in head seas at $F_{n}=0.275$

a)

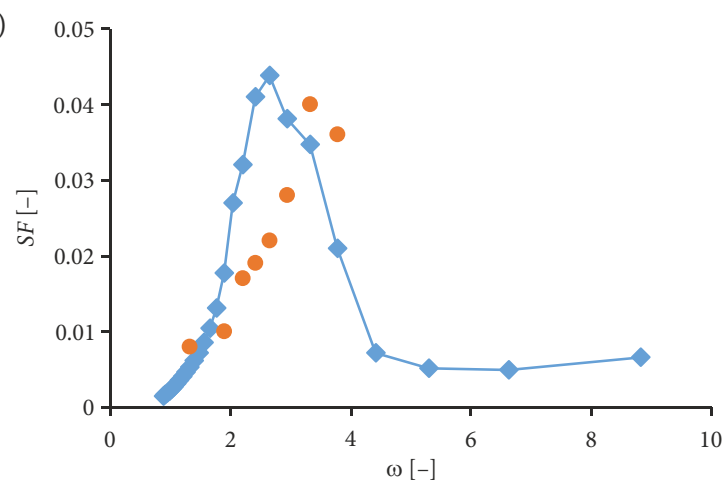

b)

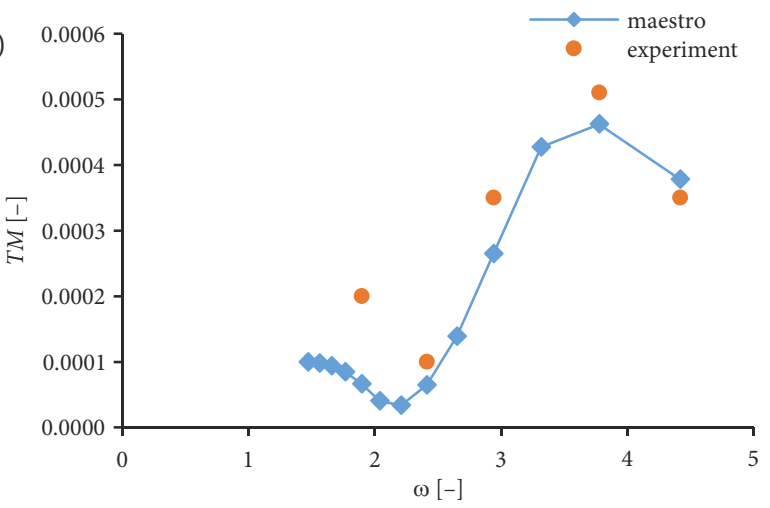

Figure 5. RAOs of vertical shear forces $S F$ (a) and longitudinal torsion moments $T M$ (b) in bow quartering seas $(\beta=150)$ at $F_{n}=0.275$

trimaran, the centre of the connected deck between the main hull and outriggers was selected. This study yields RAO curves of wave responses in the frequency-domain mode.

\subsection{Vertical bending moment}

Figures 6 and 7 present vertical bending moments RAOs at design speed. As shown in Figure 6a, vertical bending moments for beam seas are approximately the same for all three-side hull configurations at low wave frequencies. But they are different from each other at high wave frequen- cies. Figure $6 \mathrm{~b}$ shows RAOs in bow quartering seas. It can be seen that the response is linear in the frequency range of 0.50 to $0.78 \mathrm{rad} / \mathrm{s}$. Then vertical bending moments shows a nonlinear behaviour. The responses appear to be insensitive to the side hull shape at low wave frequencies as the case of beam seas.

Figure 7 shows vertical bending moments RAOs in head seas. It is observed that response is linear between a frequency range of 0.42 to $0.70 \mathrm{rad} / \mathrm{s}$. Then vertical bending moment differs for different side hull configurations 
and they also contain few kinks. These changes in the side hull form affect the response at higher frequencies in this heading. There is a clear distinction between their peak magnitudes with the inboard shape, which has the highest responses. It is evident that the outboard model performs better than the other cases.

In summary, the vertical bending moments are approximately the same for the three configurations at low frequencies for beam seas, quartering seas, and head seas but at high frequencies, they are different. It is worth noting that for beam seas and quartering seas peaks of the vertical bending moments are roughly the same for all three configurations whereas for head seas peaks are considerably different. In head seas, side hull forms affect the responses at higher frequencies and inboard shape has significantly higher peak magnitude. In all waves, heading outboard shape performs better than other cases.

\subsection{Vertical shear force}

The RAOs of vertical shear forces are presented in Figures 8 and 9.
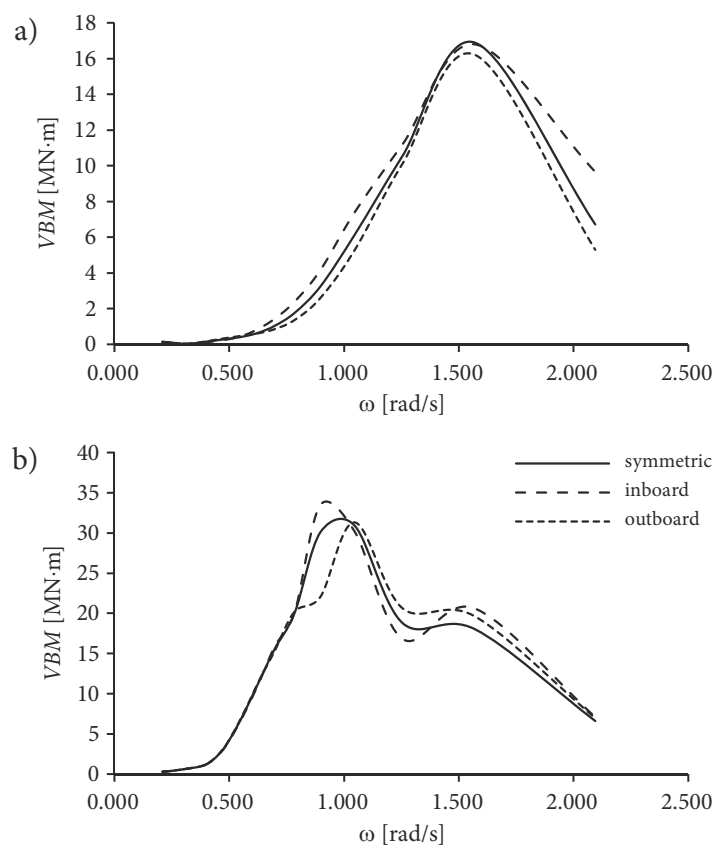

Figure 6. RAOs of vertical bending moments $V B M$ in: $\mathrm{a}$ - beam seas; $\mathrm{b}$ - bow quartering seas

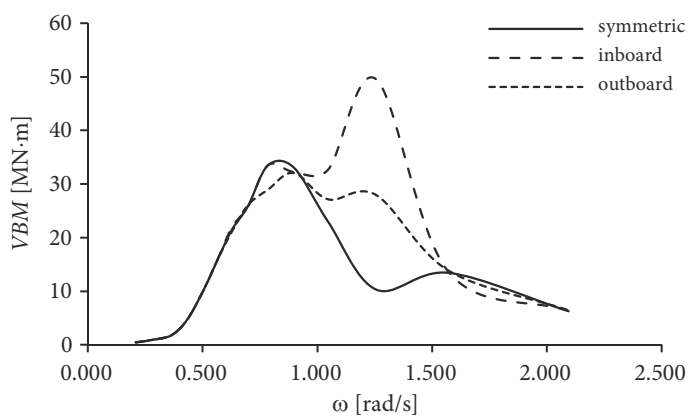

Figure 7. RAOs of vertical bending moments $V B M$ in head seas
Figure 8a presents RAOs in beam seas. It is observed that variations of vertical shear forces with frequency are generally similar to those of vertical bending moment but peak values are different for different side hull configurations for three headings. Inboard and outboard types have higher and lower peak magnitude, respectively. As shown in Figure 8b, in the bow quartering seas the response is linear for the frequency ranges from 0.42 to $0.70 \mathrm{rad} / \mathrm{s}$ similar to the vertical bending moment. The relation of RAO to wave frequency is nonlinear throughout the frequencies and they also contain fewer kinks. Type of the side hull affects the peak magnitude and inboard type has the highest response.

The vertical shear forces response in the head seas are illustrated in Figure 9. It is perceived that vertical shear forces are nonlinear for all frequencies and contains some kinks after peak frequency. Therefore, side hull configuration influences the trend and peak values. The inboard model has obviously the highest peak value. The symmetric model performs better than other ones.
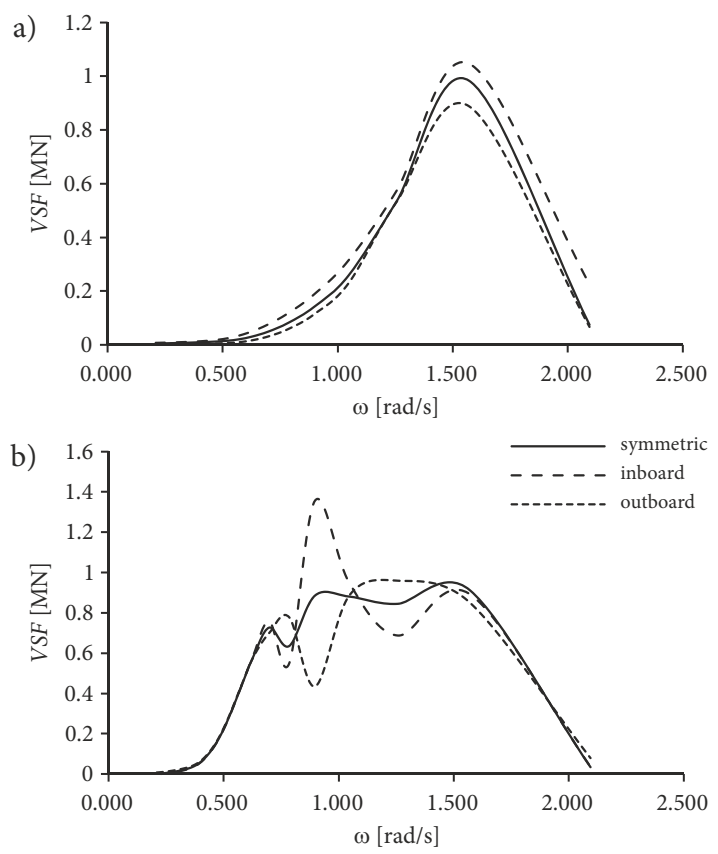

Figure 8. RAOs of vertical shear forces VSF in: $\mathrm{a}$ - beam seas; $\mathrm{b}$ - bow quartering seas

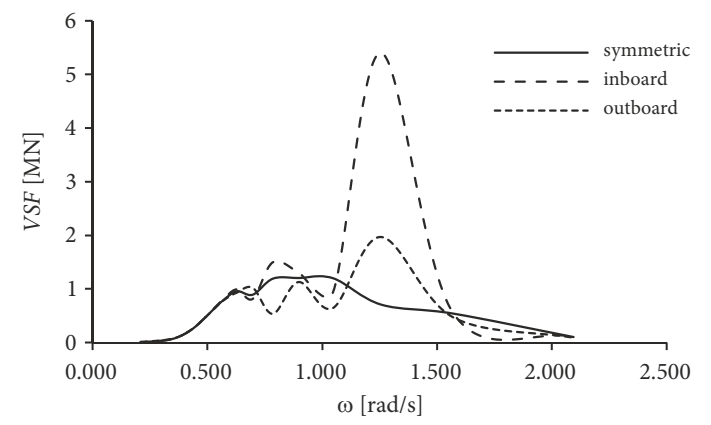

Figure 9. RAOs of vertical shear forces VSF in head seas 
In summary, peak values of vertical shear forces of symmetric and outboard side hulls are approximately the same for all headings. The inboard form shows weak performance indicated by significantly high peak values for all headings.

\subsection{Transverse bending moment}

The RAOs of transverse bending moments are presented in Figures 10 and 11.

The transverse bending moments response in the beam seas is shown in Figure 10a. The responses are nonlinear throughout the frequencies. There is a clear distinction between their peak values with the symmetric model that has the highest peak magnitude. Trend of outboard and inboard are similar and their peak magnitudes remain the same. The RAOs of transverse bending moments in the bow quartering seas are presented in Figure 10b. For this case, transverse bending moments are nonlinear for all frequencies and contain some kinks for each form of side hull. These changes in the side hull form affect the peak magnitude response of the models at lower frequency in this heading. There is a clear distinction between their
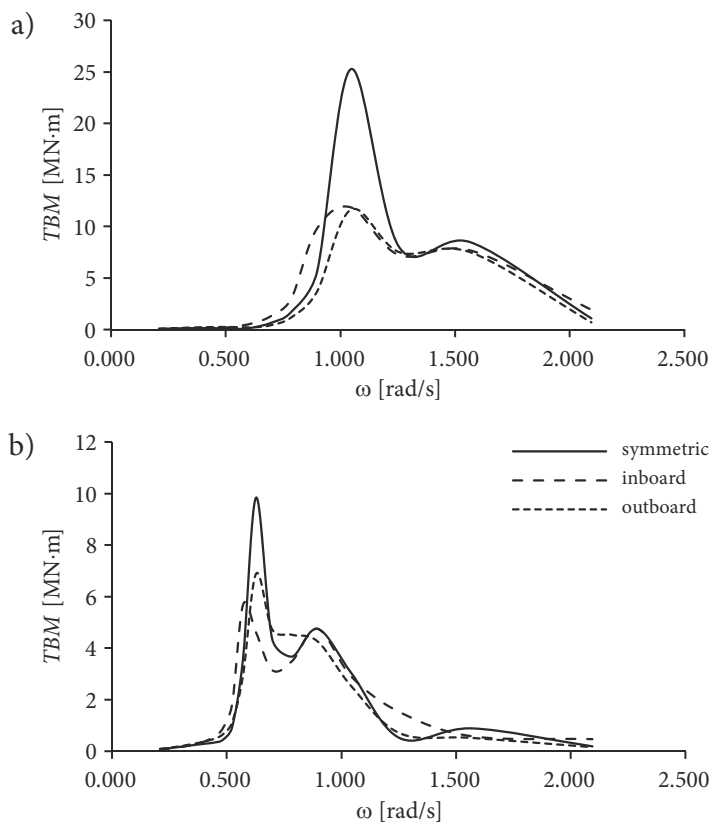

Figure 10. RAOs of transverse bending moments TBM in: $\mathrm{a}$ - beam seas; $\mathrm{b}$ - bow quartering seas

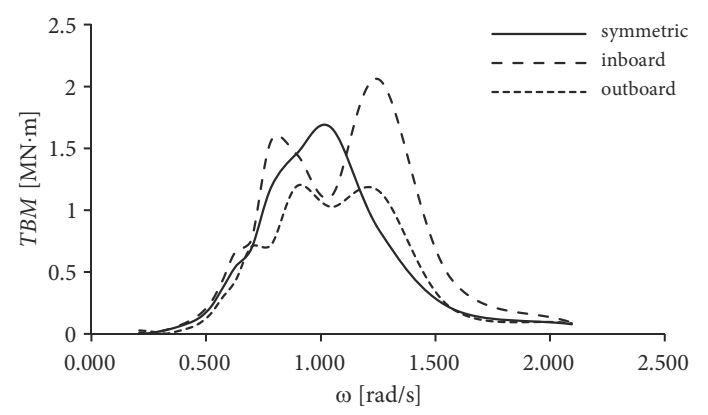

Figure 11. RAOs of transverse bending moments TBM in head seas peak magnitudes with the symmetric model that has the highest responses. It can be seen that the inboard model performs better than the other cases.

The transverse bending moments response in the head seas is depicted in Figure 11. The responses are nonlinear, and contain obvious high kink with a magnitude less than the peak magnitude. These changes in the side hull form affect the responses. Inboard has high peak magnitude and outboard with lower peak magnitude performs better than other forms.

In summary, in the beam and bow quartering seas, symmetric form affects the responses at low frequencies and has the highest peak values. Trend of responses for inboard and outboard side hull shapes is similar in beam and bow quartering seas.

\subsection{Transverse shear force}

The RAOs of transverse shear forces are shown in Figures 12 and 13.

Trends of results in the beam seas shown in Figure 12a are nonlinear for all frequencies. It is perceived that trend of transverse shear forces are similar to the transvers
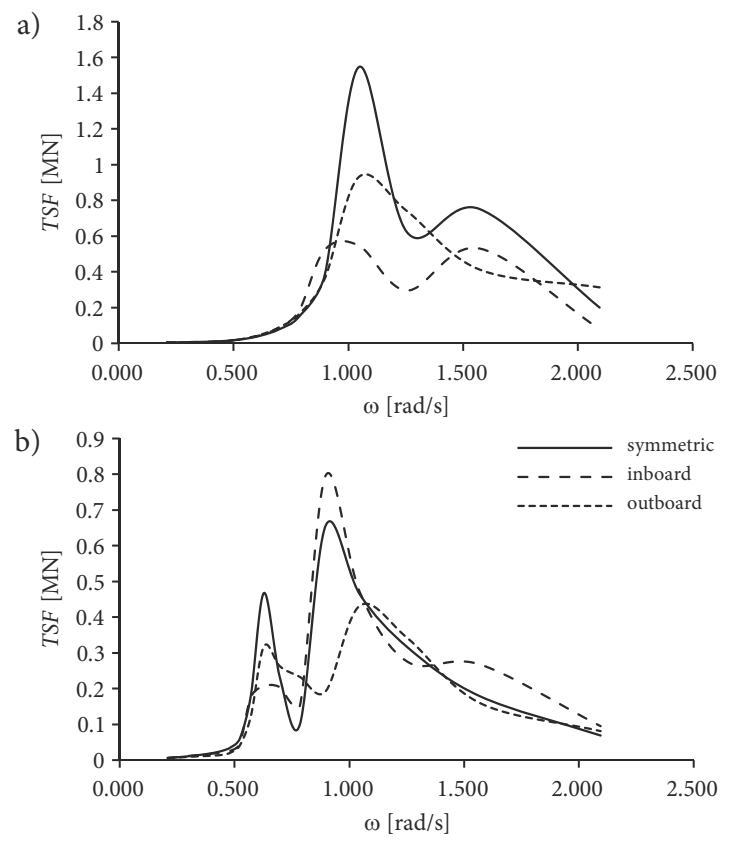

Figure 12. RAOs of transverse shear forces TSF in: $\mathrm{a}$ - beam seas; $\mathrm{b}$ - bow quartering seas

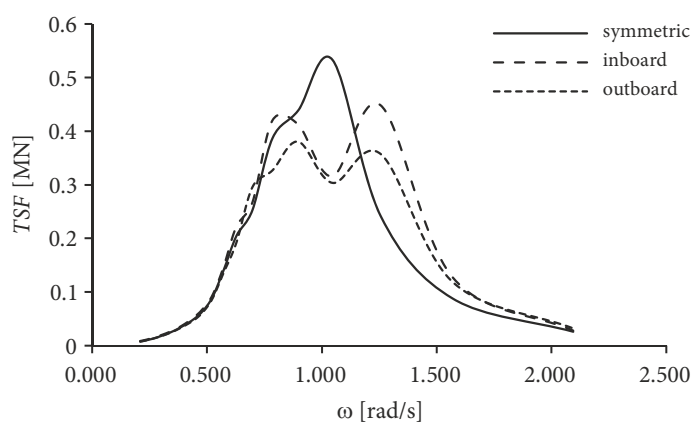

Figure 13. RAOs of transverse shear forces TSF in head seas 
bending moment but have different peak magnitudes. The distinct features of transverse shear forces are high peak magnitude for symmetric model in low frequency. The RAOs of transverse shear forces in the bow quartering seas are presented in Figures 12b. Trend of the transverse shear forces is nonlinear and contains some kinks for each forms of side hull. These changes in the side hull form affect the peak magnitude response of the models at low frequency in this heading. There is a clear distinction between their peak magnitudes with the inboard model that has the highest response. The outboard model performs better than the other cases.

The transverse shear forces response in the head seas is illustrated in Figure 13. The responses are nonlinear, and contain fewer kinks. Peak magnitude response of the models occurs at low frequencies in this heading. The trends of outboard and inboard forms are similar, but the peak magnitude of outboard form is less than the inboard shape. The peak magnitude of the symmetric is significantly higher than the other cases.

In summary, in the beam and head seas, symmetric form has the highest response values in low frequencies. In beam seas, the inboard model and in head seas outboard form perform better than the other cases. The outboard model performs better than the other models in this load condition.

\subsection{Transverse torsion moment}

Figures 14 and 15 present transverse torsion moments RAOs at design speed.

In the beam seas shown in Figure 14a, trend of results is quite similar to transverse shear forces but has higher peak magnitudes in this heading. The distinct feature of these Figures is high peak magnitude for symmetric model in low frequencies. The RAOs of transverse torsion moments in the bow quartering seas are depicted in Figure 14b. Trend of the transverse torsion moments is nonlinear and contains some kinks for each form of side hull. The distinct features of these figures are the peak magnitude response of the symmetric model, which happens at very low frequencies in this heading. The peak magnitudes of the three forms of the side hull are approximately the same.

The transverse torsion moments in the head seas are presented in Figure 15. The responses are nonlinear and contain some obvious high magnitude kink with magnitude less than the peak magnitude. Trends of the outboard and inboard forms are similar in high frequencies and peak magnitudes are approximately the same. Differences between the peak magnitudes of three models are not significant.

In summary, in the beam seas, symmetric form has the highest response values in lower frequencies. In bow quartering and head seas the difference between the peak magnitudes of three models are not significant. Performances of inboard and outboard models are similar.
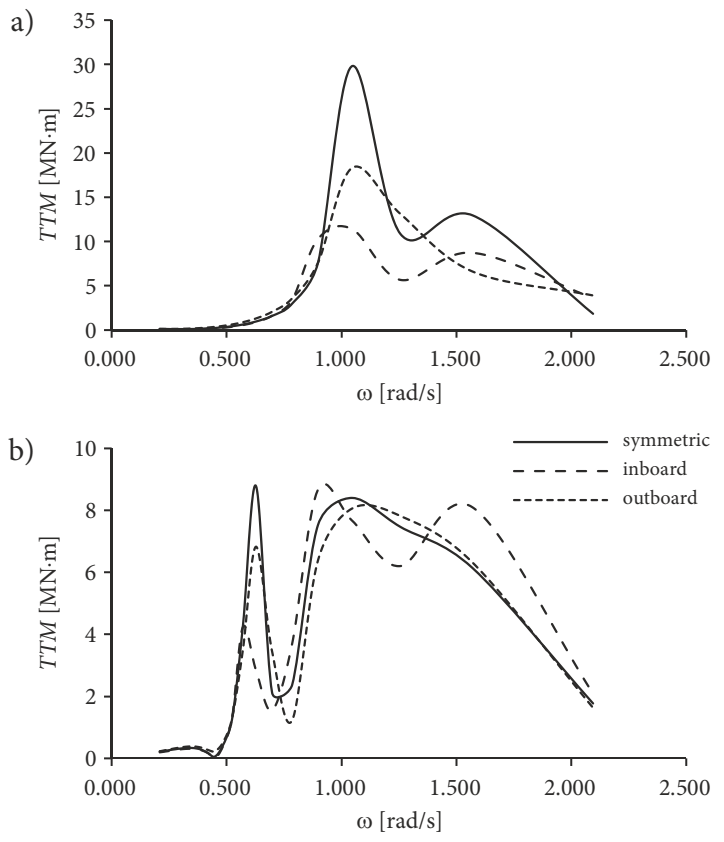

Figure 14. RAOs of transverse torsion moments TTM in: $\mathrm{a}$ - beam seas; $\mathrm{b}$ - bow quartering seas

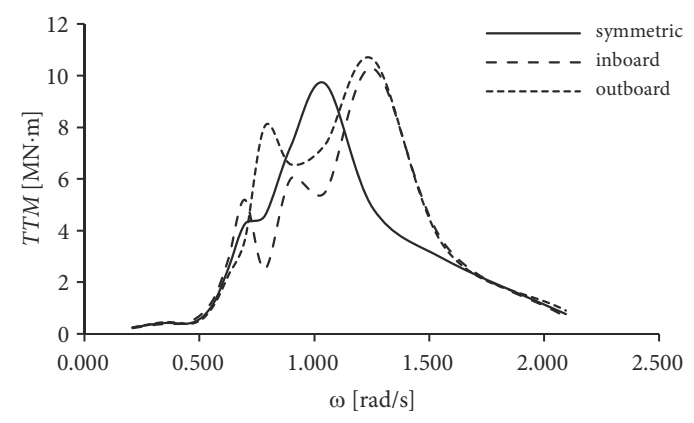

Figure 15. RAOs of transverse torsion moments TTM in head seas

\section{Conclusions}

In this article, dynamic wave-induced loads acting on cross-deck of trimaran ship with respect to different types of side hulls have been conducted using a 3D panel method code, MAESTRO-Wave. Based on the results of the study, the following conclusions are drawn:

1) the maximum vertical wave loads of cross-deck appear in head seas condition for three kinds of sidehull forms; in this heading, the inboard side hull form shows the weakest performance with significantly higher peak magnitudes;

2) the maximum transverse wave loads of cross-deck appear in beam seas condition for three kinds of side-hull forms; in this heading, the symmetric side hull form has not good performance with significantly higher peak magnitudes in low frequencies;

3 ) behaviours of the outboard and symmetric models under vertical wave-induced loads are almost the same as well as those of outboard and inboard forms under transverse wave loads; 
4) according to items 2 and 3, it is concluded that outboard form shows good performance for both vertical and transverse wave loads; the inboard and symmetric forms show weak performance in vertical wave loads and transverse wave loads, respectively;

5) the kinks in the plots are due to the coupling of the wave-induced responses and the motion's responses within the identified areas of nonlinearity;

6) the vertical bending moments in the beam and bow quartering seas are insensitive to the side hull shape.

\section{References}

ABS. 2014. Rules for Building and Classing: Steel Vessels 2014: Part 3 - Hull Construction and Equipment. American Bureau of Shipping (ABS), Houston, TX, US. 326 p. Available from Internet: https://ww2.eagle.org/content/dam/eagle/rulesand-guides/archives/conventional_ocean_service/2_svr2014/ SVR_Part_3_e-July14.pdf

Ackers, B. B.; Michael, T. J.; Tredennick, O.; Landen, H. C.; et al. 1997. An investigation of the resistance characteristics of powered trimaran side-hull configurations, Transactions - Society of Naval Architects and Marine Engineers 105: 349-373.

Bashir, M. B.; Tao, L.; Atlar, M.; Dow, R. S. 2013. Experimental and numerical investigation of the wave-induced loads on a deep- $\mathrm{V}$ catamaran in regular waves, in Proceedings of the ASME 2013 32nd International Conference on Ocean, Offshore and Arctic Engineering. Volume 5: Ocean Engineering, 9-14 June 2013, Nantes, France. https://doi.org/10.1115/OMAE2013-10212

Brizzolara, S. 2003. Effect of hulls form variations on the hydrodynamic performances in waves of a trimaran ship, in Proceedings of the 7th International Conference on Fast Sea Transportation, FAST 2003, 7-10 October 2003, Ischia, Italy, 1-8.

Dabssi, N.; Chagdali, M.; Hémon, A. 2008. Hydrodynamic coefficients and forces on multihulls in shallow water with constant or variable depth, Transport 23(3): 245-252.

https://doi.org/10.3846/1648-4142.2008.23.245-252

Dobashi, J. 2014. Influence of side hull arrangement for wave loads acting on cross deck of trimaran, Journal of the Japan Society of Naval Architects and Ocean Engineers 20: 69-75. https://doi.org/10.2534/jjasnaoe.20.69 (in Japanese).

Dyachkov, V.; Makov, J. 2005. Seakeeping of a fast displacement catamaran, Transport 20(1): 14-22. https://doi.org/10.3846/16484142.2005.9637990

Fang, M.-C.; Chen, T.-Y. 2008. A parametric study of wave loads on trimaran ships traveling in waves, Ocean Engineering 35(89): 749-762. https://doi.org/10.1016/j.oceaneng.2008.02.001

Fang, M.-C.; Too, G.-Y. 2006. The effect of side hull arrangements on the motions of the trimaran ship in waves, Naval Engineers Journal 118(1): 27-37. https://doi.org/10.1111/j.1559-3584.2006.tb00405.x

Fuentes, D.; Salas, M.; Tampier, G.; Troncoso, C. 2015. Structural design and optimisation of an aluminium trimaran, in C. G. Soares, R. A. Shenoi (Eds.). Analysis and Design of Marine Structures V, 545-553.

Kim, Y. 2010. Comparative study on linear and nonlinear ship motion and loads, in Proceedings of the ITTC Workshop on Seakeeping, V\&V for Non-Linear Seakeeping Analysis, International Towing Tank Conference, 19-21 October 2010, Seoul, Korea, 283-347.

Liu, W.; Li, X.; Wu, W.; Xu, S. 2011. Study on longitudinal ulti- mate strength analysis method for high speed trimaran, in The Twenty-First International Offshore and Polar Engineering Conference, 19-24 June 2011, Maui, Hawaii, US, 1-5.

Maestromarine. 2016. MAESTRO Version 10.0: Users' Manual. Available from Internet: http://www.maestromarine.com

Mohammadi, M.; Khedmati, M. R.; Vakilabadi, K. A. 2015. Effects of hull damage on global loads acting on a trimaran ship, Ships and Offshore Structures 10(6): 635-652. https://doi.org/10.1080/17445302.2014.943387

Ogawa, Y. 2008. Study on the prediction method of wave loads of a multi-hull ship taking account of the side hull arrangement, in HIPER'08: the 6th International Conference on HighPerformance Marine Vehicles, 18-19 September 2008, Naples, Italy, 239-247.

Ren, H.; Zhen, C.; Li, C.; Feng, G. 2012. Study on structural form design of trimaran cross-deck, in Proceedings of the ASME 2012 31st International Conference on Ocean, Offshore and Arctic Engineering. Volume 2: Structures, Safety and Reliability, 1-6 July 2012, Rio de Janeiro, Brazil, 631-636. https://doi.org/10.1115/OMAE2012-84025

Rhoads, J. L. 2004. Structural Loading of Cross Deck Connections for Trimaran Vessels. MSc Thesis, Massachusetts Institute of Technology, US. 176 p. Available from Internet: https://dspace.mit.edu/handle/1721.1/33165

Senan, A.; Krishnankutty, P. 2012. A study on non-linear wave forces and motion responses of a tri-hull carrier vessel, Proceedings of the Institution of Mechanical Engineers, Part M: Journal of Engineering for the Maritime Environment 226(1): 3-14. https://doi.org/10.1177/1475090211428106

Ungaro, A.; Pino, E.; Viviani, M.; Dattola, R. 2004. Global strength assessment of a trimaran hull multi-purpose frigate, in RINA International Conference Design \& Operation of Trimaran Ships, 29-30 April 2004, 29-30 April 2004, London, UK.

Xu, M.; Zhang, S.-L. 2011. A numerical study on side hull optimization for trimaran, Journal of Hydrodynamics, Ser. B 23(2): 265-272. https://doi.org/10.1016/S1001-6058(10)60112-6

Zhao, C.; Ma, M.; Hughes, O. 2013. Applying strip theory based linear seakeeping loads to 3D full ship finite element models, in Proceedings of the ASME 2013: 32nd International Conference on Ocean, Offshore and Arctic Engineering. Volume 5: Ocean Engineering, 9-14 June 2013, Nantes, France. https://doi.org/10.1115/OMAE2013-10124 